\title{
The Phloroglucinol Conundrum: Increase in Root Growth of Hybrid Cymbidium (Orchidaceae) with no Toxic Effect on Protocorm-like Body Formation
}

\author{
Jaime A. Teixeira da Silva*
}

Faculty of Agriculture and Graduate School of Agriculture, Kagawa University, Miki-cho, Kagawa, 761-0795, Japan

Key words: Phloroglucinol conundrum PLB, Synseed, Root growth, Teixeira Cymbidium

Research on orchid roots is limited. Yet, the ability to artificially increase root mass could be a valuable technique for applied purposes in the future, for example in the production of root-specific secondary metabolites. In this study, phloroglucinol (PG), a known rooting enhancer in many plants and an inducer of phenolic substances, was used to assess the response of excised roots and also protocorm-like bodies (PLBs) of hybrid Cymbidium Twilight Moon 'Day Light'. When half-PLBs (i.e. transversally cut PLBs) were cultured on Teixeira Cymbidium (TC) No. 1 medium, the development of new PLBs or neo-PLBs was not enhanced by the addition of any concentration of PG. In fact, 1-8 mg/l PG was toxic to neo-PLB formation, i.e. the formation of new PLBs was reduced relative to the control. In contrast, PG at $<8 \mathrm{mg} / \mathrm{l}$ significantly enhanced the length and fresh weight of roots while $8 \mathrm{mg} / \mathrm{l}$ was toxic to root growth and development. When PG was applied at $2 \mathrm{mg} / \mathrm{l}$ in liquid TC medium, root fresh weight increased by $149 \%$. Control roots not exposed to PG turned yellow and died. Although the applications of PG to orchid tissue culture is unexplored, there is a strong possibility for its application in orchid biotechnology where auxins or hairy roots induced by Agrobacterium rhizogenes might not work.

Most orchid biotechnologists would not pay much attention to roots, except for studies involving symbiotic interactions with microorganisms such as plant growth-promoting Rhizobacteria. Except for such cases, the roots of orchids remain relatively unexplored and unknown organs, despite the extent of biotechnological studies that exist on orchids (Hossain et al. 2013). Most rootrelated studies in orchids pertain to greenhouse studies related to irrigation or

*Present address: P. O. Box 7, Miki-cho post office, Ikenobe 3011-2, Kagawa-ken, 761-0799, Japan.<jaimetex@yahoo.com>. 
fertilization, phytopathology or cross sectional studies showing histological structure. One might ask, why might there be a need to mass produce orchid roots? At first, one immediate response could be that several orchids are medicinal and contain many important compounds and secondary metabolites (reviewed in part by Teixeira da Silva 2013a). As for other plants, different organs within the same plant have a different capacity to form metabolites, and even the same metabolite can be produced in vastly different quantities in aerial organs (e.g. leaves or flowers) versus roots, e.g., essential oils. Thus, even though the exact importance of increasing root mass might not be very apparent or evident at the moment, by creating protocols that can increase the mass production of roots could serve a future purpose with unknown applications. There are not many ways to generate roots de novo from roots or other organs, or to mass produce roots. Some possibilities include the use of auxins or the induction of hairy roots by Agrobacterium rhizogenes. A third option involves the use of chemical inducers using compounds that are not auxins. One such compound is phloroglucinol (1,3,5-trihydroxybenzene; PG), which is a degradation product of phloridzin, has growth-promoting properties (Teixeira da Silva et al. 2013). In this study, Cymbidium has been used as an emerging model plant due to its favorable response in vitro and clonal propagules, the protocorm-like body (PLBs), which are equivalent to orchid somatic embryos (Teixeira da Silva 2013b; Teixeira da Silva and Dobránszki 2013). When PLBs are encapsulated, the resulting synthetic seeds or synseed (Teixeira da Silva 2012a) can be useful for cryopreservation (Sharma et al. 2013).

PG has been used in some manner or form in the in vitro propagation of at least 33 plant genera (incl. about 40 - 50 species or cultivars in total) (Teixeira da Silva et al. 2013). In most of those studies, PG was not studied in isolation. Rather, it was added as an additive to a defined medium, usually in addition to other media additives. Approximately $60 \%$ of those studies resulted in improved rooting, about $30 \%$ in enhanced shoot induction or formation, while in the remaining $10 \%$ of studies, improvement in callus formation or somatic embryogenesis was observed. However, one study, and in fact the only one to date conducted thus far on an orchid, was the improved recovery of cryopreserved Dendrobium nobile seeds or protocorms (seed-derived propagules) when PG was added to the cryopreservation medium at 1\% (Vendrame and Faria 2011; Galdiano et al. 2012).

Capitalizing upon this gap in information that exists with respect to orchids, and using the assumption that PG would have some effect on organogenesis, the effect of PG on PLB induction and proliferation as well as root growth was assessed. Interestingly, most of the studies that indicated an improved 
organogenic response in fact did not include systematic studies to assess the optimal concentration of PG. Rather, most of them used a single concentration, usually based on a previously reported protocol and thus, most studies do not indicate what negative consequences, or toxic effects, that PG might have on plant growth. Many factors influence the outcome of the PLB developmental program, including the choice of plant growth regulator (PGR), culture conditions, or explants used, with new PLBs or neo-PLBs forming from PLBs (Teixeira da Silva and Tanaka 2006, Teixeira da Silva and Dobránszki 2013).

All chemicals and reagents were of the highest analytical grade available and were purchased from either Sigma-Aldrich (St. Louis, USA), Wako Chemical Co. (Osaka, Japan) or Nacalai Tesque (Kyoto, Japan), the cheapest choice at the highest tissue-culture grade, unless specified otherwise.

PLBs of hybrid Cymbidium Twilight Moon 'Day Light' (Bio-U, Japan) originally developed spontaneously from shoot-tip culture on Vacin and Went (VW, 1949) agar medium without PGRs, were induced and subcultured (PLB induction and proliferation medium or VW PLB) every two months on TC medium (Teixeira da Silva 2012b). TC, which contains unique levels of macro- and micronutrients, and which was supplemented with $0.1 \mathrm{mg} / \mathrm{l} \mathrm{NAA}$ and $0.1 \mathrm{mg} / \mathrm{l}$ $\mathrm{Kn}, 2 \mathrm{~g} / \mathrm{l}$ tryptone and $20 \mathrm{~g} / \mathrm{l}$ sucrose, and solidified with $8 \mathrm{~g} / \mathrm{l}$ Bacto agar (Difco Labs., USA), according to procedures and advice outlined by Teixeira da Silva et al. (2005) and Teixeira da Silva and Tanaka (2006). All media were adjusted to $\mathrm{pH} 5.3$ with $1 \mathrm{~N} \mathrm{NaOH}$ or $\mathrm{HCl}$ prior to autoclaving at $100 \mathrm{KPa}$ for $17 \mathrm{~min}$. Cultures were kept on $40 \mathrm{ml}$ medium in $100 \mathrm{ml}$ Erlenmeyer flasks, doublecapped with aluminum foil, at $25^{\circ} \mathrm{C}$, under a $16 \mathrm{hrs}$ photoperiod with a light intensity of $45 \mu \mathrm{mol} / \mathrm{m}^{2} / \mathrm{s}$ provided by plant growth fluorescent lamps (Homo Lux, Matsushita Electric Industrial Co., Japan). Longitudinally bisected PLB (3 - 4 $\mathrm{mm}$ in diameter) segments (hereafter termed half-PLBs), 15/flask, were used as explants for PLB induction and proliferation and for all experiments. Culture conditions and media followed the recommendations previously established for medium formulation, biotic and abiotic factors and for PLB induction, formation and proliferation (Teixeira da Silva 2012a, 2012b).

The effect of PG on neo-PLB induction from half-PLBs was assessed by adding 0 (control), 1, 2, 4 and $8 \mathrm{mg} / \mathrm{l} \mathrm{PG} \mathrm{(Sigma-Aldrich)} \mathrm{to} \mathrm{TC} \mathrm{medium.}$ Similarly, and simultaneously, 5-mm long roots with intact root tips were excised with a feather blade from 6-month-old shoots growing on plant growth regulator-free Hyponex medium solidified with $7 \mathrm{~g} / \mathrm{l}$ agar (Fig. 1, STEP 1). Using excised root tips (Fig. 1, STEP 2), the effect of PG on root growth (as isolated organs as opposed to organs attached to the rest of the plant) was assessed. Growth of roots on solid and liquid medium was assessed after 60 days. Liquid 
medium was agar-free 10 roots with intact root tips were cultured in $25 \mathrm{ml}$ of liquid TC medium containing the same concentration of PG as the solid medium trials and placed on a shaker at constant $84 \mathrm{rpm}$ under the same light and temperature conditions as solid TC medium (Fig. 1, STEP 3). The resulting organogenic outcome (neo-PLB or root response) was scored visually after 60 days, 60 days being the optimal time for sampling (Teixeira da Silva and Dobránszki 2013). Plants and roots were photographed using stereo light microscopy and/or a digital camera. Experiments were statistically designed and data were analyzed as per Teixeira da Silva (2012a, b) and significant differences between means were assumed at $\mathrm{P} \leq 0.05$.

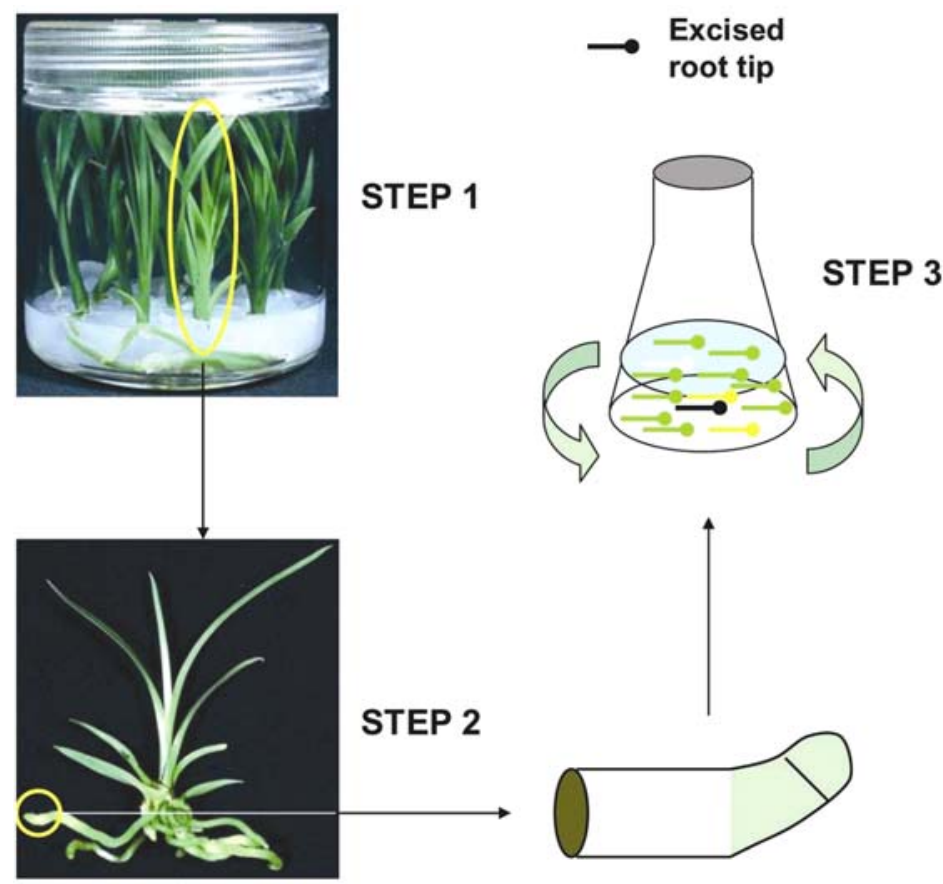

Fig. 1. Experimental design for assessing the effect of phloroglucinol (PG) on root growth and development. In STEP 1, mature plants, usually of $6-8 \mathrm{~cm}$ in height, following culture on plant growth regulator-free Hyponex medium solidified with $7 \mathrm{~g} / \mathrm{l}$ agar to stimulate thick roots, serve as the donor plants for this experiment. In STEP 2, mature plants are gently removed from the agar, remaining agar is washed off gently with sterile distilled water, and roots, including the intact root tip, are excised under sterile conditions on a clean bench. This process should be conducted rapidly to avoid oxidation of root tissue and subsequent browning in response to tissue damage. Excised roots (15/flask) are placed in $25 \mathrm{ml}$ of TC (Teixeira da Silva 2012b) liquid medium containing the same concentration of PG as the solid medium trials and placed on a shaker at constant $84 \mathrm{rpm}$ under the same light and temperature as solid TC medium, i.e., $25^{\circ} \mathrm{C}, 16 \mathrm{hrs}$ photoperiod, light intensity $=45 \mu \mathrm{mol} / \mathrm{m}^{2} / \mathrm{s} .100 \mathrm{ml}$ Erlenmeyer flasks double-capped with aluminum foil are used. In this experiment, shaking took place for 3 months. 
The key finding of this paper is that PG reduced neo-PLB formation but increased root growth. All concentrations of PG significantly decreased the number of neo-PLBs that formed on the surface of half-PLBs, the percentage of half-PLBs forming neo-PLBs and the fresh weight $(\mathrm{mg})$ of half-PLB + neo-PLBs relative to the control (PG-free TC medium) (Table 1). In contrast, PG between 1 and $8 \mathrm{mg} / \mathrm{l}$ significantly increased root weight and root length relative to the control after culture for 60 days but this increase was particularly acute in liquid

Table 1. The growth and developmental response of hybrid Cymbidium Twilight Moon 'Day Light' half-PLBs to phloroglucinol after 60 days in culture.

\begin{tabular}{|c|c|c|c|c|}
\hline Treatment & $\begin{array}{l}\% \text { of half-PLBs } \\
\text { forming } \\
\text { neo-PLBs }\end{array}$ & $\begin{array}{l}\text { Number of neo- } \\
\text { PLBs formed } \\
\text { per half-PLB }\end{array}$ & $\begin{array}{l}\text { Fresh weight } \\
(\mathrm{mg}) \text { of half- } \\
\text { PLB + neo-PLBs }\end{array}$ & Hyperhydricity ${ }^{2}$ \\
\hline $\mathrm{TC}+0 \mathrm{mg} / \mathrm{PG}^{1}$ & $100 \mathrm{a}$ & $8.3 \mathrm{a}$ & $526 a$ & - \\
\hline $\mathrm{TC}+1 \mathrm{mg} / \mathrm{l} \mathrm{PG}$ & $67 \mathrm{~b}$ & $6.1 \mathrm{~b}$ & $328 \mathrm{~b}$ & - \\
\hline $\mathrm{TC}+2 \mathrm{mg} / \mathrm{lPG}$ & $23 \mathrm{c}$ & $3.2 \mathrm{c}$ & $181 \mathrm{c}$ & - \\
\hline $\mathrm{TC}+4 \mathrm{mg} / \mathrm{lPG}$ & $6 \mathrm{~d}$ & $0.3 \mathrm{~d}$ & $71 \mathrm{~d}$ & - \\
\hline $\mathrm{TC}+8 \mathrm{mg} / \mathrm{lPG}$ & $0 \mathrm{~d}$ & $0 \mathrm{~d}$ & $56 \mathrm{~d}^{3}$ & - \\
\hline
\end{tabular}

Mean values followed by the same letter in the same column are not significantly different based on DMRT $(\mathrm{P}=0.05) . \mathrm{n}=90(10 \times 3 \times 3) . \mathrm{PG}=$ Phloroglucinol; PLB = Protocorm-like body; TC = Teixeira Cymbidium medium No. 1 (Teixeira da Silva 2012b). ${ }^{1}$ control with no PG. ${ }^{2}$ Hyperhydricity: - = No occurrence; + = occurrence. ${ }^{3}$ In fact, the average fresh weight of initial half-PLB explants is $54 \mathrm{mg}$.

medium (Table 2, Fig. 2), with as much as a $149 \%$ increase in fresh weight when culture in liquid TC with $2 \mathrm{mg} / \mathrm{l}$ PG. Even though the secondary metabolites or potential nutritional qualities of Cymbidium roots have not been explored, this protocol could serve as one method for mass producing roots (or for increasing the fresh weight of roots) of this or other orchids for which valuable compounds have been identified. It is important to emphasize that only the terminal 5-mm of roots was used to avoid possible interference from shoot-derived reserves, i.e. root development in Fig. 2 (right) is derived exclusively from medium composition, with enhanced growth and biomass resulting directly as a consequence of PG.

PG has had in most plants studied to date (Teixeira da Silva et al. 2013), a positive effect on rooting, but almost invariably, this effect has been synergistic in the presence of other auxins or PGRs, and rarely has the effect of PG exclusively been studied on root growth or development. The only study on an orchid, Dendrobium nobile, using PG indicated the improved recovery of cryopreserved encapsulated seed or protocorms (Vendrame and Faria 2011, Galdiano et al. 2012). PG, a precursor in the lignin biosynthesis pathway, was 
used to prevent hyperhydricity in micropropagation by providing precursors which normally are synthesized at low levels or not synthesized at all in hyperhydric tissues and by increasing the activity of enzymes involved in lignin synthesis (Phan and Hegedus 1985, Ross and Grasso 2010). Most plant responses

Table 2. Root growth and development of hybrid Cymbidium Twilight Moon 'Day Light' in response to phloroglucinol after 60 days in culture.

\begin{tabular}{|c|c|c|c|}
\hline Treatment & $\begin{array}{l}\text { Length of roots } \\
(\mathrm{mm}) \text { [Increase in } \\
\text { root length }(\%)]\end{array}$ & $\begin{array}{l}\text { Fresh root weight } \\
(\mathrm{mg}) \text { [Increase in } \\
\text { root weight }(\%)]\end{array}$ & Hyperhydricity ${ }^{2}$ \\
\hline $\begin{array}{l}\text { Initial roots } \\
\text { (day } 0 \text { of culture) }\end{array}$ & $5.0 \mathrm{c}[0]^{3}$ & 103 e $[0]^{4}$ & - \\
\hline $\mathrm{TCs}+0 \mathrm{mg} / 1 \mathrm{PG}^{1}$ & $5.3 c(6)$ & $147 \mathrm{~cd}(43)$ & - \\
\hline $\mathrm{TCs}+1 \mathrm{mg} / \mathrm{l} \mathrm{PG}$ & $5.9 \mathrm{~b}(18)$ & 163 c (58) & - \\
\hline $\mathrm{TCs}+2 \mathrm{mg} / \mathrm{PG}$ & 7.8 a (56) & 181 bc (76) & - \\
\hline $\mathrm{TCs}+4 \mathrm{mg} / \mathrm{l} \mathrm{PG}$ & 5.6 bc (12) & $126 \mathrm{~d}(22)$ & - \\
\hline $\mathrm{TCs}+8 \mathrm{mg} / 1 \mathrm{PG}$ & $5.3 c(6)$ & $118 \mathrm{~d}(15)$ & - \\
\hline $\mathrm{TC}_{\mathrm{L}}+0 \mathrm{mg} / 1 \mathrm{PG}^{1}$ & $5.4 \mathrm{bc}(8)$ & 192 bc (86) & + \\
\hline $\mathrm{TC}_{\mathrm{L}}+1 \mathrm{mg} / \mathrm{l} \mathrm{PG}$ & $5.6 \mathrm{bc}(12)$ & $201 \mathrm{~b}(95)$ & + \\
\hline $\mathrm{TC}_{\mathrm{L}}+2 \mathrm{mg} / \mathrm{PG}$ & $6.2 \mathrm{~b}(24)$ & 256 a (149) & + \\
\hline $\mathrm{TC}_{\mathrm{L}}+4 \mathrm{mg} / \mathrm{PG}$ & $6.0 \mathrm{~b}(20)$ & $237 \mathrm{ab}(130)$ & + \\
\hline $\mathrm{TC}_{\mathrm{L}}+8 \mathrm{mg} / \mathrm{PG}$ & $5.8 \mathrm{~b}(16)$ & 179 bc (74) & + \\
\hline
\end{tabular}

Mean values followed by the same letter in the same column are not significantly different based on DMRT $(P=0.05)$ when compared to initial length ${ }^{3}$ and fresh weight $t^{4}$ of roots at day 0 of culture. $\mathrm{n}=90(10 \times 3 \times 3) . \mathrm{PG}=$ phloroglucinol; $\mathrm{PLB}=$ Protocorm-like body; TC = Teixeira Cymbidium medium No. 1 (Teixeira da Silva 2012b); TCs = solid (8 g/l Bacto agar) TC medium; TC $C_{\mathrm{L}}=$ Liquid TC medium. ${ }^{1}$ control with no PG. ${ }^{2}$ Hyperhydricity: - = No occurrence; + = Occurrence
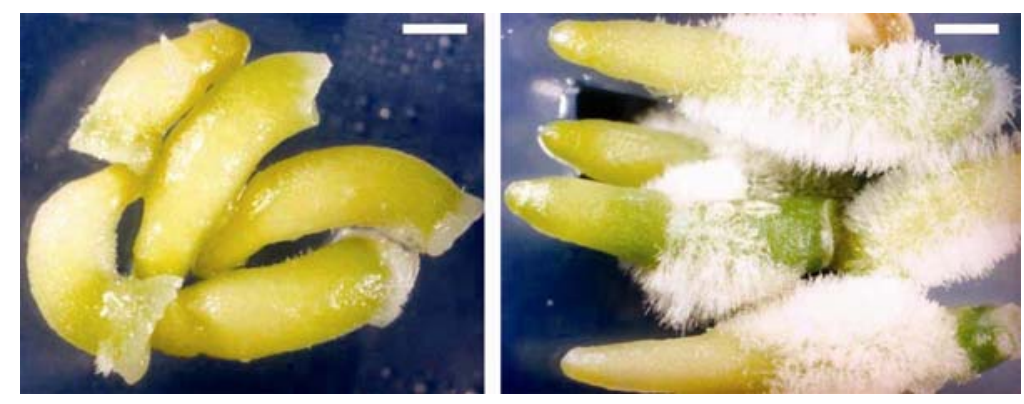

Fig. 2. Root growth and development of hybrid Cymbidium Twilight Moon 'Day Light' was enhanced following the addition of $2 \mathrm{mg} / \mathrm{l}$ phloroglucinol (PG) (right) relative to (left) no PG in solid basal TC (Teixeira da Silva 2012b) medium. Bars $=1 \mathrm{~mm}$.

(particularly those studies involving enhanced rooting in the presence of an auxin; Teixeira da Silva et al. 2013) to phenols, including PG, involve a synergism with auxins, particularly IAA, thus the mode of action is likely dependent on the 
regulation of internal IAA levels in which oxidative catabolism of IAA results in the loss of auxin activity (Normanly et al. 2004). PG has occasionally been found to have inhibitory effects (George et al. 2010) although is difficult to propagate hardwood species like apple, PG is essential for root formation (Dobránszki and Teixeira da Silva 2010, Magyar-Tábori et al. 2010). These apparently contradictory effects of PG on plant organogenesis in vitro are understandable if we observe the results of this study. At only limited concentrations was PG stimulatory to root growth, while PG was, overall, toxic to neo-PLB formation (Tables 1,2). This study confirms that PG may be considered as a new class of plant growth regulator.

\section{Acknowledgement}

The author thanks Prof. Michio Tanaka for research support.

\section{References}

Dobránszki J and Teixeira da Silva JA (2010) Micropropagation of apple - a review. Biotechnol. Adv. 28(4): 462-488.

Galdiano Jr. RF, Lemos EGM, Faria RT and Vendrame WA (2012) Cryopreservation of Dendrobium hybrid seeds and protocorms as affected by phloroglucinol and Supercool X1000. Sci. Hort. 148:154-160.

George EF, Hall MA and De Klerk GJ (2010) The growth regulatory effects of phenols. In: George EF, Hall MA, De Klerk GJ (Eds) Plant Propagation by Tissue Culture, $3^{\text {rd }}$ ed. Springer, The Netherlands, pp. 192-196.

Hossain MM, Kant R, Van PT, Winarto B, Zeng S-J and Teixeira da Silva JA (2013) The application of biotechnology to orchids. Critical Rev. Plant Sci. 32(2): 69-139.

Magyar-Tábori K, Dobránszki J, Bulley SM, Teixeira da Silva JA and Hudák I (2010) In vitro shoot regeneration in apple - role of cytokinins. Plant Cell Tiss. Org. Cult. 101: 251-267.

Normanly J, Slovin JP and Cohen JD (2004) Hormone biosynthesis, metabolism and its regulation. In: Davies PJ (Ed.) Plant hormones: Biosynthesis, signal transduction, action! Kluwer Academic Publishers, Dordrecht, The Netherlands, pp. 36-62.

Phan CT and Hegedus P (1985) Possible metabolic basis for the developmental anomaly observed in in vitro culture, called 'vitreous plants'. Plant Cell Tiss. Org. Cult. 6: 83-94.

Ross S and Grasso R (2010) In vitro propagation of 'Guayabo del país' (Acca sellowiana (Berg.) Burret). Fruit Veg. Cereal Sci. Biotech. 4 (special issue 1): 83-87.

Sharma S, Shahzad A and Teixeira da Silva JA (2013) Synseed technology - A complete synthesis. Biotechnol. Adv. 31(2): 186-207.

Teixeira da Silva JA (2012a) Production of synseed for hybrid Cymbidium using protocorm-like bodies. J. Fruit Ornamental Plant Res. 20(2): 135-146. 
Teixeira da Silva JA (2012b) New basal media for protocorm-like body and callus induction of hybrid Cymbidium. J. Fruit Ornamental Plant Res. 20(2): 127-133

Teixeira da Silva JA (2013a) Orchids: advances in tissue culture, genetics, phytochemistry and transgenic biotechnology. Floriculture Ornamental Biotech. 7(1): 1-52.

Teixeira da Silva JA (2013b) The role of thin cell layers in regeneration and transformation in orchids. Plant Cell Tiss. Org. Cult. 113(2): 149-161.

Teixeira da Silva JA and Dobránszki J (2013) How timing of sampling can affect the outcome of the quantitative assessment of plant organogenesis. Sci. Hortic. 159: 59-66.

Teixeira da Silva JA, Dobránszki J and Ross S (2013) Phloroglucinol in plant tissue culture. In Vitro Cell. Dev. Biol. - Plant. 49(1): 1-16.

Teixeira da Silva JA and Tanaka M (2006) Embryogenic callus, PLB and TCL paths to regeneration in hybrid Cymbidium (Orchidaceae). J. Plant Growth Reg. 25(3): 203-210.

Vacin E and Went FW (1949) Some pH changes in nutrient solutions. Bot. Gaz. 110: 605613.

Vendrame WA and Faria RT (2011) Phloroglucinol enhances recovery and survival of cryopreserved Dendrobium nobile protocorms. Sci. Hortic. 128: 131-135. 